\title{
Relationship between Athletic Identity, Sports Motivation and Dispositional Optimism among College Students Participating in Individual Sports
}

\author{
Ankita Dandekar ${ }^{1}$, Jenifer Chandani ${ }^{2}$, Archana Patki ${ }^{3}$ \\ ${ }^{1}$ Post graduate student \\ ${ }^{2}$ Assistant Professor \\ ${ }^{3}$ Professor and Head \\ Department of Psychology, Smt Maniben M.P. Shah Women's College of Arts and Commerce, Mumbai \\ Email-anks94@gmail.com \\ Corresponding author - Ms. Ankita Dandekar
}

\begin{abstract}
Introduction: Sports has been an integral part of all the cultures including the Indian culture. India has been developing rapidly when it comes to the sports participation and representation at the world level. Thus it has become apparent to find out the factors that promote sports participation, improve sports performance and maintain the performance further. This study tries to focus on such variables that might be the key to improving sports performance in the elite level college going athletes. The study investigates three variables Athletic Identity, Sports Motivation and Dispositional Optimism.

Methodology: The data was collected using the Athletic Identity Measurement Scale (AIMS) for Athletic Identity, Sports Motivation Scale-28(SMS-28) for Sports Motivation factor and Life Orientation Test (LOT-R) for Dispositional Optimism. The data was collected from the population of 100 college going elite level athletes through purposive sampling method. The population consisted of athletes participating in various individual sports at the state, national and international level. It was a co-relational study trying to find out whether there exists a relationship between the three variables.

Results: Results displayed a very poor and non-significant correlation between three levels of Athletic Identity and Dispositional Optimism (Exclusivity and Dispositional Optimism $r=0.081$ ); Social Identity and Dispositional Optimism $(r=-0.064)$ and Negative Affectivity and Dispositional Optimism $(r=0.129)$ and the R-Square value was found to be non-significant.

Conclusions: It can be concluded from this study that there exists no significant relationship between Dispositional Optimism and Athletic Identity or Sports Motivation and Athletic Identity. Thus there is a need to explore further into other factors promoting sports participation.
\end{abstract}

Key Words: athletic identity, dispositional optimism, intrinsic motivation, extrinsic motivation, sports motivation.

(Paper received $-5^{\text {th }}$ June 2017 , Peer review completed $-8^{\text {th }}$ July 2017 , Accepted $-10^{\text {th }}$ July 2017)

\section{INTRODUCTION}

The sports culture is developing in India since the Indus Valley civilization. It continues to today's modern sports and is flourishing ever since. Sports can be called as an activity involving physical exertion and skill in which an individual or team competes against another based on certain arbitrary set of rules. Ancient Indian history is said to have rich knowledge of sports and physical activities [1]. India first participated at the Olympic Games in 1900, with a single athlete Norman Pritchard [2]. Since then, the participation in the Olympics has been increasing. However according to a research done, as compared to other countries - 
for example, total number of participation from USA was 558 athletes, Russia 278 and China 416 - the participation of India was only 120 athletes [3]. These facts further give rise to the need for identification of the factors that contribute towards sports participation, persistence, efforts and success. As established by Daniel Gould and Sarah Carson, sports participants who have reportedly higher levels of coaching behaviour (competition strategies, goal setting, etc) talked about how sport lessons are related to life and built a positive rapport with athletes. They also reported that development of emotional regulation, cognitive skills, feedback, pro-social norms and linkages to community were parts of the characteristic of their higher school sports experience [4]. Neighbourhood, household, and individual factors can explain socioeconomic inequalities in sports participation to a large extent [5].

Sallis and McKenzie [6] showed that positive experiences in physical education in childhood influences people's engagement in adult life which in turn improves public health. Research clearly shows that regular exercise is a positive predictor of good health. A lot of research focuses on personality and on social and environmental characteristics of a person engaging in regular exercise [7], but innate biological mechanisms are considered as important additional factors influencing exercise behaviour [8]. The inborn drive to exercise will be most obvious seen in leisure-time (i.e., self-chosen) exercise behaviour that can be operationalized as regular participation in sports [9]. A greater resemblance of mono zygotic twins makes a strong case for the contribution of genetic factors to individual differences in sports participation [10]. Thus, from these studies, it can be concluded that, Sports Participation is basically dependent on Social, Environmental, Personality and Genetic factors.

\section{ATHLETIC IDENTITY}

\section{The Two Sides of Athletic Identity}

Nasco and Wedd [11], describe two faces or two types of Athletic Identity,viz. Private Identity and Public identity. Private identity is concerned with how an individual sees himself or herself and is unavailable for public scrutiny - it includes our attitudes, beliefs, feelings and emotions. Public identity on the other hand is concerned with how an individual thinks about how others see him or her, or indeed may judge him or her. According to Role-Identity Theory, an individual is likely to base his or her actions on how he or she likes to see himself or herself and how he or she like to be seen by others.

They also say that an individual always ranks his or her identities according to his or her relative salience. The identity with the greatest salience is the strongest or is seen distinctively in that individual. For majority of athletes, the highest ranked identity will be that relating to their sport, e.g. 'I am a runner'; 'I am a cyclist'; 'I am a hockey player'. This phenomenon can be called as 'Athletic Identity', which is commonly defined as 'the degree to which a person identities with the role of an athlete. 'In this instance, private athletic identity refers to the extent to which the individual thinks and feels like an athlete whilst public athletic identity is the extent to which an individual is known and recognized by others as an athlete.

According to Stryker and Macke [12], identity salience can be conceptualized as the probability of the activation of a given role behaviour in a given situation. For example if one's athletic identity is strong, he or she is likely to make athletic choices in other contexts as well. This could mean choosing to leave a party early and getting enough sleep (athlete role behaviour) over staying with friends (social role behaviour).

\section{The Up and the Down Side of Athletic Identity}

In many researchers' view, having strong Athletic Identity is an essential part of being an 'elite athlete'. Having a strong Athletic Identity is advantageous when it comes to commitment in training and a focus on sport related goals; possessing the motivation and discipline necessary for intense training and success in high level sport; positive effects on athletic performance and improved social relationships etc. But on the other hand too strong an athletic identity may result in an over-commitment to the role of an athlete resulting in sometimes dangerous and dysfunctional practices - including over training [13]. 


\section{Structural and Cognitive Identity Theory}

Stryker and Burke [14] discussed Structural Identity Theory and Cognitive Identity Theory, two different but strongly related theories of identity development. Structural Identity Theory examines the influences of external components such as society and groups within society (e.g., family, friends, coaches, teachers, the media and sport) on the individual. On the other hand, Cognitive Identity Theory explores the impact of internal components on the individual such as evaluation and interpretation of the identities within the self. Both external and internal components play important roles in the socialization process that contributes to the formation, maintenance, and abandonment of identities such as athletic identity. The interaction between the Structural Identity and Cognitive Identity form the advanced Athletic Identity i.e. how social structures (i.e., external components) and self-evaluation (i.e., internal components) affect the structure of the self and social behaviour. For example, Brewer and his colleagues [15] in studies verified that males identified more with sport than females, as did athletes compared to non-athletes.

\section{The Three Factor Model}

Brewer and Cornelius [16] developed a model consisting of three first order factors that are subordinate to one higher athletic identity factor (figure 1.1). Brewer and his colleagues [17] indicate that the construct of athletic identity consists of social identity, exclusivity and negative affectivity factors. The social identity factor is "the extent to which the individual views him/herself as occupying the role of the athlete" within society [18]. The exclusivity factor is "the extent to which an individual's self-worth is determined solely by performance in the athlete role. Negative affectivity is represented by two items and it is "the extent to which an individual experiences negative effect in response to undesirable outcomes" of sport participation.

\section{THEORY OF DISPOSITIONAL OPTIMISM}

\section{Dispositional Optimism}

Charles Carver and Michael Scheier coined the term 'dispositional optimism' to describe their approach the global expectation that good things will be plentiful in the future and bad things scarce. They argued that optimism is associated with and leads to, securing positive outcomes whereas pessimism is associated with greater negative outcomes [19]. For example, in studies of young adults, optimism has been found to be associated with greater life satisfaction [20] whereas pessimism has been found to be associated with greater depressive symptoms. Carver and Scheier see optimism as dispositional. They have found that optimists report fewer physical symptoms, better health habits and better coping strategies. Even among a group who had experienced the bad outcome of being diagnosed with breast cancer [21] found that optimistic personality types experienced less distress, engaged in more active coping and were less likely to engage in avoidance or denial strategies.

\section{Explanatory Style}

Arising from Seligman's famous "learned helplessness" research in the 70 s and 80 s, i.e. the reaction of giving up when faced with the belief that whatever you do does not matter, was the related concept of "explanatory style". This was developed from the analysis and patterns of how people explained events that happened to them. Seligman developed this analysis into the field of optimism with several other colleagues. He authored the books Learned Optimism and later The Optimistic Child to highlight the relationship between optimism and pessimism and certain styles of explanatory style. Seligman claimed in the former book, "An optimistic explanatory style stops helplessness, whereas pessimistic explanatory style spreads helplessness". Seligman developed attributional retraining to help people "learn optimism". According to this perspective, those who explain away bad events with internal (caused by themselves), stable (will continue to occur) and global (will happen in other spheres of life) causes are described as pessimistic whilst those who favour external, unstable and specific causes are described as optimistic [2223]. The theory was devised in the context of learned helplessness and, as such, it may rely too heavily on the notion that the absence of pessimism creates optimism. The application of "learned optimism" focuses on reducing helplessness / depression through the cognitive therapy models developed by Beck [24] and 
Ellis [25]. These cognitive behavioural techniques may not actually be teaching people "optimism", but instead may just be reducing pessimism. Peterson, himself a proponent of explanatory style, warns that "Research on optimism (i.e. optimistic explanatory style) will not be as substantial if it remains closely tied to helplessness theory" [26].

\section{Optimism and Athletes}

A study done by Stephanie [27] tried to find out optimism level among college going athletes. Results provide support that a possible relationship does exist between athletic participation and optimism levels. The reasons provided for these significant differences may be due to increases in self- efficacy and mastery challenges provided by athletic participation. Another study [28] tried to find out the level of optimism and health behaviour in athletes. The level of pessimism in these athletes was average. The female athletes were less pessimistic than the female controls. A similar, highly significant difference occurred between the male athletes and non-athletes. Gender did not differentiate the level of optimism in either group. Among the women, optimism correlated with healthy practices, such as daily sleep and recreation habits, or physical activity. The greater the pessimism increased, positive attitudes declined in the female controls, the female athletes, and the male controls. The athletes displayed greater optimism than the controls. Among the women, optimism correlated with good health practices.

In a study, researchers [29] he tried to find out about Superstition, Personal Control, Optimism and Pessimism. Optimism and Pessimism did not affect athletes' overall practice of superstitious behaviours. Athletes who had lesser beliefs in God-mediated control were less likely to be optimistic. A lesser belief in God-mediated control emerged as a slight predictor of less belief in the effectiveness of superstitions and therefore, less usage of superstitious behaviours.

The role of the current study was to examine the relationship between three variables viz. Athletic identity, Dispositional Optimism and Sports Motivation.

\section{MATERIALS AND METHODS}

The study was done on 100 College going athletes (50 males and 50 females) who engage into individual sports. The age range of the participants will be 17 years to 22 years which is the average age range of college going population in Mumbai. Athletes will be from the sports of Gymnastics, Karate, Judo, Fencing, Shooting, Chess, Table Tennis and Badminton. These athletes will be recruited on the basis of a checklist containing their demographic details, level of sports participation (state level, national level and international level), years of engagement into professional sports etc. Various Sports Complexes, Sports Academies and Institutions will be approached for the recruitment of the participants. Athletes who practice sports on a professional level i.e. who participate at the state, national or international level and are engaging in the same sports for more than 2 years consecutively will be the participants in this study.

\section{Tools Used in the Study -}

\section{Athletic Identity}

Athletic Identity was measured using the Athletic Identity Measurement Scale (AIMS) [30]. The AIMS consists of 7 statements concerning the athletes' perception of their identity in relation to sport. For each item, subjects responded on a scale from 1 (strongly disagree) to 7 (strongly agree). The 7-item AIMS instrument was supported as both a unidimensional instrument [31] and a multidimensional instrument [32-33]. The evaluation of the unidimensional scale can be performed on the total scores of all items which range from 7 to 49 , with higher scores indicating stronger athletic identity. The unidimensional AIMS instrument indicated a very good internal consistency of 0.81 . The multidimensional scale contains three subscales, social identity, exclusivity and negative, with each subscale being evaluated on the basis of the 1-7 score. In this study both the multidimensional scale as well as unidimensional scale will be used. The AIMS has shown a high internal consistency in several studies (coefficient alphas of $0.93,0.87$ and 0.81 ) and sufficient retest reliability $(r=0.89)$ [34]. Content Validity was found to be high. 


\section{Sports Motivation}

Sports Motivation Scale (SMS) was developed by Pelletier and others [35]. It is a 28 item scale measuring Intrinsic and Extrinsic Sports Motivation and Amotivation. It is a 7 point likert scale where 1 stands for 'does not correspond at all' and 7 stands for 'Corresponds Exactly'. The internal consistency reliability was found to be between 0.74 to 0.80 . Validity was found to be high among college students.

\section{Dispositional Optimism}

Life Orientation Test (LOT-R) developed by Scheier and Carver [36]. It is a 10 item scale with positively and negatively framed statements. It is a five point likert scale where $\mathrm{A}=\mathrm{I}$ agree a lot, $\mathrm{B}=\mathrm{I}$ agree a little, $\mathrm{C}=\mathrm{I}$ neither agree nor disagree, $\mathrm{D}=\mathrm{I}$ Disagree a little and $\mathrm{E}=\mathrm{I}$ disagree. The LOT-R demonstrated an acceptable level of internal consistency, with a Cronbach's alpha of 0.76 across different western populations.

\section{RESULTS}

The purpose was to examine whether a relationship exists between three levels of Athletic Identity viz. Exclusivity, Social Identity and Negative Affectivity and Dispositional Optimism, as well as to investigate a relationship between 2 levels of Sports Motivation viz. Intrinsic Sports Motivation and Extrinsic Sports Motivation.

Table 1 illustrates the Mean and the SD for the analysis 1 which involves Predictor Variable-Athletic Identity measured at 3 levels (Social Identity, Exclusivity and Negative Affectivity) and Criterion Variables Dispositional Optimism. It demonstrates that the mean for the factor of Dispositional Optimism was found to be 21.13 whereas the SD was obtained to be 2.856. The Mean for the 3 levels of Athletic Identity viz. Exclusivity, Social Identity and Negative Affectivity were found to be 7.81, 6.14 and 4.31 respectively where as the SD were found to be 3.650, 2.227 and 2.207 respectively

Table 2 shows correlations between Dispositional Optimism and 3 Levels of Athletic Identity Viz. Exclusivity, Social Identity and Negative Affectivity. The correlation between Exclusivity and Dispositional Optimism was found to be $\mathrm{r}=0.081$ (NS). The correlation seems to be positive but very weak correlation which was found to be non-significant. The correlation between Social Identity and Dispositional Optimism was found to be $r=-0.064$. It shows that the correlation was found to be negative weak correlation which was found to be non-significant. The correlation between Negative Affectivity and Dispositional Optimism was found to be $r=0.129$. which was found to be positive but very low and nonsignificant. Thus, the correlation between Athletic Identity and Dispositional Optimism was found to be very low and insignificant.

The Mean and the SD of Predictor Variable-Sports Motivation are measured at 2 levels (Intrinsic Sports Motivation and Extrinsic Sports Motivation) and so are that of the Criterion Variables - Athletic Identity (Unidimensional) measured. Results demonstrated that the mean for the variable of Athletic Identity (UniDimensional) was found to be 38.33 whereas the SD was 16.512.The Mean for the 2 levels of Sports Motivation viz. Intrinsic Sports Motivation and Extrinsic Sports Motivation were found to be 71.37 and 63.88 respectively where as the SD were found to be 7.655 and 12.968 respectively.

The correlation between Intrinsic Sports Motivation and Athletic Identity was found to be $r=0.024$. The correlation seems to be positive but very weak correlation which was found to be non-significant. The correlation between Extrinsic Sports Motivation and Athletic Identity was found to be $r=0.015$. which was found to be positive but very low and non-significant. Thus, the correlation between Sports Motivation and Athletic Identity was found to be very low and insignificant.

The Model Summary of Multiple Linear Analysis computed with the predictor variable being Sports Motivation measured at two levels Intrinsic Sports Motivation and Extrinsic Sports Motivation and the criterion variable being Athletic Identity was also calculated. The $\mathrm{R}$ Square value was found to be not significant. Thus, it implied that no significant predictors were established. 
Table 1 - Descriptive Statistics: Dispositional Optimism, Exclusivity, Social Identity and Negative Affectivity

\begin{tabular}{|l|c|c|c|}
\hline \multicolumn{2}{|c|}{ Mean } & Std. Deviation & N \\
\hline Dispositional Optimism & 21.13 & 2.856 & 99 \\
\hline Exclusivity & 7.81 & 3.650 & 99 \\
\hline Social Identity & 6.14 & 2.227 & 99 \\
\hline Negative Affectivity & 4.31 & 2.207 & 99 \\
\hline
\end{tabular}

Table 2 - Correlation between Dispositional Optimism and 3 Levels of Athletic Identity Viz. Exclusivity, Social Identity and Negative Affectivity

\begin{tabular}{|l|c|c|c|c|}
\hline \multicolumn{2}{|c}{$\begin{array}{c}\text { Dispositional } \\
\text { Optimism }\end{array}$} & Exclusivity & Social Identity & $\begin{array}{c}\text { Negative } \\
\text { Affectivity }\end{array}$ \\
\hline $\begin{array}{l}\text { Dispositional } \\
\text { Optimism }\end{array}$ & 1.000 & 0.081 & -0.064 & 0.129 \\
\hline Exclusivity & 0.081 & 1.000 & 0.080 & 0.167 \\
\hline Social Identity & -0.064 & 0.080 & 1.000 & 0.304 \\
\hline $\begin{array}{l}\text { Negative } \\
\text { Affectivity }\end{array}$ & 0.129 & 0.167 & 0.304 & 1.000 \\
\hline
\end{tabular}

\section{DISCUSSION}

The first research question examined the relationship between Dispositional Optimism and Athletic Identity. It was initially expected that the factors would relate in the following manner: (a) Exclusivity would be a better predictor of Dispositional Optimism as compared to Social Identity and Negative Affectivity (b) Social Identity would be a better predictor of Dispositional Optimism as compared to Exclusivity and Negative Affectivity (c) Negative Affectivity would be a better predictor of Dispositional Optimism as compared to Exclusivity and Social Identity. As seen, the results of the current study are contrary to those of studies published in the past. As there is a very weak and non-significant correlation established between the variables of the first model, it may be impossible to determine which level of Athletic Identity can be a predictor of Dispositional Optimism. Thus, it can be concluded that Athletic Identity and Dispositional Optimism have a very weak correlation and that Athletic Identity was found to be a comparatively weak predictor of Dispositional Optimism. However, there can be other factors detrimental to presence of optimism in a sports person

Optimism of an athlete is primarily dependent on the external factors like behaviours displayed by the coaches. A study done [37] shows that there were differences in the preferred approach of the coach between the athletes screened as having Low levels of Optimism and athletes screened to be having high levels of optimism. These differences were highlighted best in the category with the high optimistic theme 'Encourages' implying preference for a coach to focus on present emotions in order to attain future success while the low optimistic theme 'Reassures' implies the preference for a coach to focus on past successes in order to attain success in the present. A cross-country research done [38] also showed that there was significant correlation between coaching behaviours and the optimism levels of the athletes. Thus, it can be understood that coach's behaviour with their athletes becomes a major contributing factor in cultivating optimism among athletes.

Another contributing factor could be the Coping Strategies used by the athletes in the event of failures. Gould, Dieffenbach, and Moffett [39] reported that Olympic champions report high levels of mental 
toughness, coping effectiveness, and optimism. Optimism,in this respect, has been defined as "a major determinant of the disjunction between two classes of behavior: (a) continued striving versus (b) giving up and turning away". More optimistic individual exhibit increased effort to achieve goals. Alternatively, less optimistic individuals are more likely to withdraw or disengage attempts at achieving a goal [40].

Finally, optimism appears to be associated with differences in coping behaviour. More optimistic individuals use more approach coping strategies and less avoidance strategies [41]. In a population of Professional athletes, Optimism was significantly co-related with 8 types of Coping Strategies viz. Mental Imagery, Effort Expenditure, Thought Control, Seeking Support, Relaxation, Logical Analysis ,Mental Distraction and Resignation. Thus, Coping Style of an athlete can be further explored to understand the development of Optimism among athletes [42].

The second research question investigated the relationship between Sports Motivation and Athletic Identity. It was initially expected that the factors would relate in the following manner: Intrinsic Sports Motivation would be a better predictor of Athletic Identity as compared to Extrinsic Sports Motivation and vice-versa. As can be seen the results on the current study were found to be contrary. As there is a very weak and non-significant correlation established between the variables of the second model, it was not possible to determine which level of Sports Motivation can be a predictor of Athletic Identity. Thus, it can be concluded that Athletic Identity and Sports Motivation have a very weak correlation and that Sports Motivation was found to be a comparatively weak predictor of Sports Motivation.

The findings contradict the previous research done on the similar lines where researchers [43] tried to examine the Athletic Identity and Motivation among former College Athletes. Results suggest that exercise identity and athletic identity are both positively related to physical activity in former college athletes, and the identity - physical activity relationship was only partially mediated by self-determined forms of motivation. Exercise identity was a stronger predictor of self-determined motivation and physical activity compared to athletic identity. There was a significant interaction effect between exercise identity and athletic identity such that having a higher exercise identity strengthened the athletic identity - physical activity relationship.

A major reason that could contribute to the development of Athletic Identity can be attributed to the mere age of the target population. As the students enter the college, they get exposed to various other types of identities which may cause them to reduce their focus from their identity as an athlete. Athletic identity is defined as the degree of importance, strength and exclusivity attached to the athletic role maintained by athletes and influenced by their environment [44]. Regarding athletic identity and year in school, this study found no significant differences in result across grade levels. This data contradicts prior research [45] that found the athletic role in collegiate student-athletes became stronger and more exclusive with age.

Other factors relating to the age of the client could be the physical, bodily changes that an athlete goes through. The adolescence and the young adulthood is a span of human development where a person goes through a lot of hormonal as well as other bodily changes. Thus, there are certain techniques or elements in their sports performance that they could perform very easily as a child but now are unable to perform those. This could lead to the fluctuations in their Identity as an athlete. Another factor that could be the possible explanation for distorted Athletic Identity could be the retirement or debut into the competitive sports. Each sport has its own time of debut and retirement into competitive participation. For eg. Sports like Gymnastics and Swimming have majority players retiring between the ages of 18 to 22 whereas, in sports like Badminton and Tennis, 16 years onwards is the age where the players make their debut in the competitive sports. Thus, the athletic identity of a person at his or her debut is very much lower to another athlete who has comparatively more experience of competition. Similarly, as the sports person moves towards retirement, his or her athletic identity seems to be reducing as compared to what it was at the top of his or her career. As can be seen further in the ancillary observations section, majority of the participants in the targeted population were either debutants or reaching their retirement from competitive sports, this could be a contributing factor to the lower scores obtained on the variable of Athletic Identity. The age between 16 to 22 brings about a significant change in an athlete's thoughts, decision making processes, perceptions about oneself etc. which gives rise to a phenomenon called 'Identity Foreclosure'. Identity Foreclosure is a stage of self-identity discovery in which an individual has an identity but hasn't 
explored other options or ideas. An identity foreclosed individual is defined as one "who has failed to thoughtfully investigate available roles, yet who has made a premature, serious commitment to a socially prescribed role" [45]. A study done suggested that the concepts of identity hierarchies, salience, and identity foreclosure can be used to provide a better understanding of the identity structures and possibly behaviours of student athletes. It has been suggested that a highly salient athletic identity may lead to identity foreclosure in student-athletes. This may be especially disconcerting for student-athletes competing on the collegiate level as they often face pressures to excel athletically from a variety of sources.

A major factor affecting the motivation is the motivational climate that the athletes encounter. In a qualitative study done by researchers [46], they tried to find out the importance of the motivational climate in early-career sports participants created by Coach, parent and peer influences and how this factors influence sport motivation The analysis indicated that young athletes experience a motivational climate which shows consistencies with existing models of motivation. The influences of coaches related most strongly to the manner in which they perform their roles of instruction and assessment, whereas parents' influences were most salient in terms of the way they support the child's participation and learning. Both parents and coaches exerted influences through their leadership styles, affective responses and preperformance behaviours. Peers influenced participants' motivation through competitive behaviours, collaborative behaviours, evaluative communications and through their social relationships. This study provides an insight into the motivational climate experienced by young athletes and helps to delineate the different roles of social agents in influencing their motivation.

\section{REFERENCES}

1. Duguay AM, Loughead TM, Munroe-Chandler KJ. The development, implementation, and evaluation of an athlete leadership development program with female varsity athletes. Sport Psychol 2016;30(2):154-66.

2. Tadié A, Mangan JA, Chaudhuri S, editors. Sport, Literature, Society: Cultural Historical Studies. Routledge; 2016.

3. Majumdar B. Commonwealth games 2010: the index of a" new" India?. Social Research: An International Quarterly. 2011;78(1):231-54.

4. Gould D, Voelker DK. Youth sport leadership development: Leveraging the sports captaincy experience. J Sport Psychol Action 2010;1(1):1-4.

5. Roters J, Logan AJ, Meisner BA, Baker J. A preliminary study of perceptions of aging in athletes and nonathletes. Psychol Sport Exercise 2010;11(1):67-70.

6. Sallis JF, Alcaraz JE, McKenzie TL, Hovell MF, Kolody B, Nader PR. Parental behavior in relation to physical activity and fitness in 9-year-old children. Am J Dis Children 1992;146(11):1383-8.

7. Rogers MA, King DS, Hagberg JM, Ehsani AA, Holloszy JO. Effect of 10 days of physical inactivity on glucose tolerance in master athletes. J Appl Physiol 1990;68(5):1833-7.

8. Rowland T, Goff D, Popowski B, DeLuca P, Ferrone L. Cardiac responses to exercise in child distance runners. Int J Sports Med 1998;19(06):385-90.

9. Faigenbaum AD, Kraemer WJ, Blimkie CJ, Jeffreys I, Micheli LJ, Nitka M, Rowland TW. Youth resistance training: updated position statement paper from the national strength and conditioning association. J Strength Condition Res 2009;23:S60-79.

10. Maia JA, Thomis M, Beunen G. Genetic factors in physical activity levels: a twin study. Am J Prev Med 2002;23(2):87-91.

11. Nasco SA, Webb WM. Toward an expanded measure of athletic identity: The inclusion of public and private dimensions. J Sport Exer Psychol 2006;28(4):434-53.

12. Stryker S, Burke PJ. The past, present, and future of an identity theory. Soc Psychol Quart 2000;2:284-97.

13. Cotterill ST, Symes R. Integrating social media and new technologies into your practice as a sport psychology consultant. Sport Exercise Psychol Rev 2014;10(1):55-64.

14. Stryker S. Identity theory and personality theory: Mutual relevance. J Personality 2007;75(6):1083-102.

15. Good AJ, Brewer BW, Petitpas AJ, Van Raalte JL, Mahar MT. Identity foreclosure, athletic identity, and college sport participation. The Academic Athletic Journal. 1993;8:1-2.

16. Brewer BW, Cornelius AE, Stephan Y, Van Raalte J. Self-protective changes in athletic identity following anterior cruciate ligament reconstruction. Psychol Sport Exercise 2010;11(1):1-5.

17. Stephan Y, Brewer BW. Perceived determinants of identification with the athlete role among elite competitors. J Appl Sport Psychol 2007;19(1):67-79. 
18. Hale BD, James B, Stambulova N, Collins D. A cross cultural analysis of the dimensions of the athletic identity measurement scale: A herculean undertaking. Int J Sport Psychol 1999;30(83):100-8.

19. Horton R, Mack D. Athletic identity in marathon runners: Functional focus or dysfunctional commitment?. J Sport Behav 2000;23(2):101-9.

20. Chang EC, Maydeu-Olivares A, D'Zurilla TJ. Optimism and pessimism as partially independent constructs: Relationship to positive and negative affectivity and psychological well-being. Personal Individ Diff 1997;23(3):433-40.

21. Carver CS. Adult attachment and personality: Converging evidence and a new measure. Personal Soc Psychol Bull 1997;23(8):865-83.

22. Hiroto DS, Seligman ME. Generality of learned helplessness in man. J Personal Soc Psychol 1975;31(2):311-22.

23. Miller WR, Seligman ME. Depression and learned helplessness in man. J Abnorm Psychol 1975;84(3):228-50.

24. Clak DA, Beck AT. Scientific foundations of cognitive theory and therapy of depression. John Wiley \& Sons; 1999.

25. Ellis A. Rational-emotive therapy. Big Sur Recordings; 1973.

26. Alloy LB, Peterson C, Abramson LY, Seligman ME. Attributional style and the generality of learned helplessness. J Personal Soc Psychol 1984;46(3):681-98.

27. Dember WN, Martin SH, Hummer MK, Howe SR, Melton RS. The measurement of optimism and pessimism. Curr Psychol 1989;8(2):102-19.

28. Lipowski M. Level of optimism and health behavior in athletes. Medical science monitor: Int Med J Exp Clin Res 2012;18(1):CR39.

29. Czech DR, Burke KL, Joyner AB, Hardy CJ. An exploratory investigation of optimism, pessimism and sport orientation among NCAA Division I college athletes. Int Sports J 2002;6(2):136-44.

30. Skinner N, Brewer N. Adaptive approaches to competition: Challenge appraisals and positive emotion. J Sport Exercise Psychol 2004;26(2):283-305.

31. Houle JL, Brewer BW, Kluck AS. Developmental trends in athletic identity: A two-part retrospective study. J Sport Behav 2010 Jun 1;33(2):146-66.

32. Shachar B, Brewer BW, Cornelius AE, Petitpas AJ. Career decision-making, athletic identity, and adjustment difficulties among retired athletes: A comparison between coaches and non-coaches. Kinesiol Slovenica 2004;10(1):71-85.

33. Visek AJ, Hurst JR, Maxwell JP, Watson JC. A cross-cultural psychometric evaluation of the athletic identity measurement scale. J Appl Sport Psychol 2008;20(4):473-80.

34. Murphy GM, Petitpas AJ, Brewer BW. Identity foreclosure, athletic identity, and career maturity in intercollegiate athletes. Sport Psychol 1996;10(3):239-46.

35. Pelletier LG, Tuson KM, Fortier MS, Vallerand RJ, Briere NM, Blais MR. Toward a new measure of intrinsic motivation, extrinsic motivation, and amotivation in sports: The Sport Motivation Scale (SMS). J Sport Exercise Psychol 1995;17(1):35-53.

36. Scheier MF, Carver CS, Bridges MW. Distinguishing optimism from neuroticism (and trait anxiety, self-mastery, and self-esteem): a reevaluation of the Life Orientation Test. J Personal Soc Psychol 1994;67(6):1063-80.

37. Roorda AC. An Examination Between High and Low Optimistic NCAA Division I Student-Athletes' Perceptions of Preferred Leadership Behavior in Sport: A Qualitative Investigation.

38. Van Raalte JL, Cornelius AE, Andrews S, Diehl NS, Brewer BW. Mental health referral for student-athletes: Web-based education and training. J Clin Sport Psychol 2015;9(3):197-212.

39. Udry E, Gould D, Bridges D, Beck L. Down but not out: Athlete responses to season-ending injuries. J Sport Exercise Psychol 1997;19(3):229-48.

40. Gaudreau P, Blondin JP. Different athletes cope differently during a sport competition: A cluster analysis of coping. Personal Individ Diff 2004;36(8):1865-77.

41. Solberg PA, Halvari H. Perceived autonomy support, personal goal content, and emotional well-being among elite athletes: mediating effects of reasons for goals. Percept Motor Skills 2009;108(3):721-43.

42. Buchholz A, Mack H, McVey G, Feder S, Barrowman N. BodySense: An evaluation of a positive body image intervention on sport climate for female athletes. Eating Disord 2008;16(4):308-21.

43. Reifsteck EJ, Gill DL, Labban JD. "Athletes" and "exercisers": Understanding identity, motivation, and physical activity participation in former college athletes. Sport Exercise Perform Psychol 2016;5(1):25-35.

44. Cieslak TJ. Describing and measuring the athletic identity construct: Scale development and validation (Doctoral dissertation, The Ohio State University).

45. Miller PS, Kerr GA. The role experimentation of intercollegiate student athletes. Sport Psychol 2003;17(2):196219. 
46. Keegan RJ, Harwood CG, Spray CM, Lavallee DE. A qualitative investigation exploring the motivational climate in early career sports participants: Coach, parent and peer influences on sport motivation. Psychol Sport Exer 2009;10(3):361-72.

Acknowledgements - Nil;

Source of Funding - Nil

Conflict of Interest - Nil 